\title{
Analisis Ikonologi Iklan Billboard Go-Pay di Yogyakarta
}

\author{
Dinda Destiana Fahma Ayu ${ }^{1}$ \\ ${ }^{1}$ Side Channel Ahmad Dahlan, Universitas Ahmad Dahlan, Indonesia
}

\begin{tabular}{|c|c|}
\hline Article Info & ABSTRACT \\
\hline Article history: & Penelitian ini berjuan untuk mengetahui bagaimana analisis Ikonologi iklan \\
\hline Received August 26, 2018 & $\begin{array}{l}\text { billboard Go-Pay di Yogyakarta. Dalam penelitian ini penulis memakai } \\
\text { metode penelitian Deskriptif Kualitatif. Adapun subjek utama penelitian dan }\end{array}$ \\
\hline Accepted October19, 2018 & bahan utama yang akan dikaji dan dianalisa adalah iklan "Billboard Go-Pay" \\
\hline & $\begin{array}{l}\text { di Yogyakarta, sedangkan objek pada penelitian ini akan difokuskan pada } \\
\text { ideologi yang terkandung pada pesan iklan billboard "Go-pay" di Yogyakarta }\end{array}$ \\
\hline Keywords: & $\begin{array}{l}\text { dengan menggunakan analisis ikonologi oleh Gillian Dyer. Data diperoleh dari } \\
\text { observasi dan dokumentasi. Hasil dalam penelitian yang telah dilakukan maka }\end{array}$ \\
\hline Iklan & dapat disimpulkan bahwa makna ideologi dalam iklan billboard Go-Pay adalah \\
\hline Billboard & mudah, efisien dan aman. Artinya, Iklan billboard Go-Pay di Yogyakarta \\
\hline Go-Pay & menawarkan hal yang memberikan kemudahan melakukan berbagai \\
\hline Ideologi & pembayaran, menawarkan efisiensi (mudah dan cepat) dan menjamin \\
\hline Ikonologi & $\begin{array}{l}\text { keamanan bertransaksi karena seluruh transaksi tercatat dalam sistem dan } \\
\text { untuk dapat mengakses Go-Pay pelanggan harus memasukkan kata sandi dan } \\
\text { memasukkan kode OTP yang dikirim Go-Jek melalui nomor yang terdaftar. } \\
\text { Dengan demikian, pelanggan tidak perlu merasa takut kehilangan saldo } \\
\text { apabila handphone hilang. }\end{array}$ \\
\hline
\end{tabular}

This is an open access article under the CC BY-SA license.

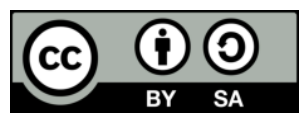

\section{Corresponding Author:}

Dinda Destiana Fahma Ayu,

Side Channel Ahmad Dahlan, Universitas Ahmad Dahlan, Indonesia,

Email: dinda@comm.uad.ac.id

\section{PENDAHULUAN}

Dalam sejarah peradaban manusia sebelum terbentuknya uang sebagai alat pembayaran yang sah seperti saat ini, awalnya manusia melakukan kegiatan transaksi pembayaran dengan cara tukar menukar barang antar manusia yang dikenal dengan istilah barter. Lalu, seiring dengan perkembangan zaman maka muncullah uang sebagai alat pembayaran yang sah. Alat pembayaran ini terus mengalami perubahan dimulai dari uang logam, uang kertas, hingga uang elektronik. Inovasi pembayaran elektronik ini muncul karena adanya tuntutan kecepatan dan efisiensi waktu dalam proses transasksi jual beli. Pembayaran elektronik ini memudahkan masyarakat dalam melakukan transaksi dan juga dirasa efisien untuk menghemat waktu, serta aman. Tidak hanya perbankan saja, akan tetapi perusahaan telekomunikasi dan perusahaan teknologi finansial ikut serta berlomba-lomba menawarkan produk e-money. Meskipun sama-sama sebagai alat pembayaran dalam bentuk uang elektronik, e-money yang dikeluarkan oleh perbankan berbeda dengan uang elektronik yang dibuat oleh perusahaan startup yang sering disebut dengan e-wallet. Salah satu jenis dari e-wallet adalah aplikasi Go-Pay dari Go-Jek. Biasanya e-money dibuat dalam bentuk fisik kartu yang tertanam basis chip didalamnya sedangkan e-wallet seperti go-pay merujuk pada uang elektronik yang basisnya pada server, sehingga pada saat proses penggunaan konsumen harus terkoneksi terlebih dahulu dengan server penerbit dan internet (Wahab, 2013).

Go-Pay berupaya menciptakan kemudahan dan kenyamanan bertransaksi. Namun pada saat ini Go-Pay sudah dapat melakukan pembayaran di berbagai mitra yang telah bekerjasama. Bahkan, Go-Jek telah mendapatkan penghargaan dari Bank Indonesia sebagai perusahaan fintech Teraktif Pendukung Gerakan 
Nasional Non Tunai (GNNT) Inklusi dan Edukasi Keuangan serta Pemberdayaan UMKM pada tahun 2017. Go-pay juga menjadi uang elektronik terpopuler pada tahun 2017, hal ini berdasarkan survei yang dilakukan oleh JakPat untuk startup report 2017 DailySocial.Id. Guna memperkenalkan layanan jasa yang ditawarkan agar dapat memenuhi keinginan konsumennya, ada banyak cara yang dilakukan oleh perusahaan gojek, salah satunya adalah dengan beriklan. Apabila dilhat secara luas iklan dapat dikatakan sebagai sebuah kegiatan mengkomunikasikan, menarik perhatian serta membujuk sebagian atau seluruh masyarakat untuk mengambil tindakan dalam menanggapi ide, barang, maupun jasa yang ditawarkan. Iklan dapat dilakukan dengan berbagai media, salah satunya adalah media luar ruang yaitu billboard. Billboard dianggap efektif untuk beriklan dikarenakan sifat media luar ruang yang dapat dibaca berulang ulang dan dapat memilih target (Wibowo, 2013).

Billboard termasuk jenis iklan luar ruang (outdoor advertising) yang paling banyak digunakan di Indonesia (Durianto, Widjaja, \& Supratikno, 2003). Fungsi billboard sendiri adalah sebagai media promosi untuk menyampaikan pesan yang terkandung. Go-Jek memiliki keinginan untuk menjadi sebuah merek yang otentik dan inovatif. Oleh karena itu go-jek sering kali memasang iklan dengan mengangkat tema yang dekat dengan permasalahan yang terjadi pada kehidupan sehari-hari. Pada saat ini ini Go-Jek sedang gencar mempromosikan tentang Go-Pay, ada beberapa versi iklan Go-Pay yang sudah dipasang pada titik-titik jalan tertentu di Yogyakarta. Iklan-iklan tersebut dikemas dengan visual yang berbeda-beda dengan isi pesan yang berbeda pula. Tampilan visual yang disuguhkan pada iklan Go-Pay tidak rumit namun menarik untuk dilihat, hal tersebut dikarenakan iklan yang dibuat tidak selalu dengan tema mendapatkan keuntungan cashback serta cara dalam melakukan pembayaran. Akan tetapi, iklan Go-Pay terlihat berbeda dikarenakan dibalik tampilan visualnya mengandung nilai-nilai ideologi yang ingin disampaikan kepada masyarakat. Terdapat tiga iklan billboard Go-Pay yang telah ditemukan oleh penulis (Durianto, 2001). Lokasi iklan billboard pertama yang ditemukan berada di titik Jalan Colombo, iklan ini memiliki tampilan visual yaitu seorang driver Go-Jek terlihat sedang menggendong anak yang mengenakan seragam sekolah dasar dipunggungnya. Iklan ini juga dilengkapi dengan teks yang bertuliskan ucapan terimakasih atas tip Go-Pay yang sudah diberikan oleh pelanggan. Lalu yang kedua, lokasi iklan billboard yang ditemukan berada di Jalan Laksda Adisucipto. Iklan yang kedua dibuat dengan tampilan visual yang menggambarkan tiga orang yang sedang makan bersama, pada iklan ini terdapat isi pesan yang dituliskan dengan kalimat "Silahturahmi makin hangat buka bareng jadi hemat". Selanjutnya yang ketiga lokasi iklan billboard ditemukan berada di Jalan Jendral Sudirman. Iklan ini mempunyai gambaran visual yakni seorang driver Go-Jek sedang bersama penumpangnya, iklan ini juga memiliki isi pesan yang dituliskan pada iklan tersebut yaitu "Tenang nariknya kalau kastamer bayar pakai Go-Pay. Gak usah nyiapin kembalian (Powell, 2012)."

Kemudian, iklan billboard Go-Pay ini akan dianalisis menggunakan teori ikonologi dari Gillian Dyer yakni pemaknaan dalam suatu karya dengan melalui tiga tahap pertama, tingkatan denotatif (makna tersurat), konotatif (makna tersirat), dan makna ideologis (pandangan hidup yang melatarbelakangi iklan tersebut). Berdasarkan latar belakang tersebut, penulis ingin melakukan penelitian tentang pesan nilai atau ideologi yang terkandung dibalik tampilan visual iklan billboard Go-Pay yang berada titik-titik kota Yogyakarta yaitu, di Jl. Colombo, Jl. Laksda Adisucipto, dan Jl. Jendral Sudirman (Johar, 2015).

\section{METODE}

Adapun kajian pustaka yang digunakan peneliti terdiri dari dua macam yang pertama adalah penelitian yang telah dilakukan sebelumnya dalam bentuk jurnal. Kemudian yang kedua adalah landasan teori sebagai pendukung penelitian yang berkaitan dengan iklan, billboard, pesan dalam iklan, dan ikonologi (Ratna, 2001).

Dalam penelitian ini penulis memakai penelitian Deskriptif Kualitatif. Subjek utama penelitian adalah iklan "Billboard Go-Pay" di Yogyakarta dan objek pada penelitian ini akan difokuskan pada ideologi yang terkandung pada pesan iklan billboard "Go-pay" di Yogyakarta dengan menggunakan analisis ikonologi oleh Gillian Dyer. Sumber data terdiri atas data primer yang bersumber dari dokumentasi peneliti berupa foto-foto iklan billboard Go-Pay yang ada di Yogyakarta. Kemudian data sekunder pada penelitian ini diperoleh melalui penelitian kepustakaan (Library Research). Adapun teknik pengumpulan data dilakukan dengan cara observasi, dan dokumentasi (Sugiyono, 2016).

\section{HASIL DAN PEMBAHASAN}

Selama penelitian ini dilakukan yaitu pada bulan Mei 2019, peneliti menemukan 3 billboard Go-Pay yang dipasang di spot premium yaitu di pinggir jalan besar sekitar Kampus Universitas Negeri Yogyakarta (UNY) Jalan Colombo, di pusat kota yaitu di Jalan Jendral Sudirman dan di sekitar bandar udara yaitu di Jalan Laksda Adisutjipto Yogyakarta. Pemasangan billboard sangat eksklusif karena tidak berdesak-desakan dengan billboard lainnya. Pada umumnya, perusahaan yang akan beriklan billboard memilih dan menganggap spot ramai sebagai spot yang efektif. Hal tersebut dikarenakan spot ramai memiliki peluang besar macet dan memungkinkan iklan terbaca oleh banyak orang. Untuk itu, sebaiknya perusahaan yang akan beriklan di 
billboard hendaknya membuat tema dan isi iklan sebaik mungkin (efektif).

\subsection{Hasil Pengamatan iklan Billboard Go-Pay di Yogyakarta}

Unsur visual billboard 1 terdiri dari tiga bagian yaitu logo Go-Pay, main visual yang bergambar seorang driver PT. Go-Jek yang menggendong anaknya sambil tersenyum bahagia dan base line yang bergambar sosial media yang dapat dikontak yaitu akun Instagram, Twitter, Facebook dan Youtube. Unsur verbal bollboard 1 terdiri dari dua bagian yaitu terletak pada headline dan tagline. Headline billboard 1 berbunyi "Berkat tip GOPAY Mas dan Mbak, saya bisa beliin seragam buat anak". Adapun tagline billboard 1 adalah "Lebih Baik Pakai Go-Pay".

Billboard 2. Unsur visual billboard 1 terdiri dari tiga bagian yaitu logo Go-Pay, main visual berupa foto driver go-jek bernama Darma dan pelanggannya. Kemudian base line yang bergambar sosial media yang dapat dikontak yaitu akun Instagram, Twitter, Facebook dan Youtube. Unsur verbal bollboard 1 terdiri dari dua bagian yaitu terletak pada headline dan tagline. Headline billboard 1 berbunyi "Tenang nariknya, kalau kastamer bayar pakai GO-PAY. Gak usah nyiapin kembalian”.

Billboard 3. Unsur visual billboard 3 terdiri dari tiga bagian yaitu logo Go-Pay, main visual yang bergambar ilustrasi sekelompok orang yang bahagia ketika melakukan buka puasa bersama. Adapun pada base line bergambar sosial media yang dapat dikontak yaitu akun Instagram, Twitter, Facebook dan Youtube. Unsur verbal. Unsur verbal bollboard 3 terdiri dari Headline berbunyi "Silaturahmi Makin Hangat Buka Bareng Jadi Hemat". Adapun sub headline iklan billboard 3 berbunyi "Nikmati Cash Back di Rekan Usaha Favoritmu" dan tagline billboard 3 adalah "Lebih Baik Pakai Go-Pay”.

\subsection{Pemaknaan}

Makna Denotasi. Makna denotasi pada billboard 1 adalah seorang driver PT. Go-Jek yang bahagia setelah mendapatkan uang tip dari pelanggan. Uang tersebut dapat dibelikan seragam sekolah untuk anaknya yang saat ini sedang menduduki bangku Sekolah Dasar (SD). Ucapan terimakasih tersebut disampaikan dengan kalimat: "Berkat tip Go-Pay Mas \& Mbak, saya bisa beliin seragam buat anak. Makasih, ya."

Makna Konotasi. Background yang digunakan putih bersih sehingga foto Pak Darman dan anaknya terlihat menonjol. Pandangan subyek ketika difoto tajam dan lurus ke depan menggambarkan sifat optimis. Artinya, optimis bahwa dengan menjadi driver PT. Go-Jek beliau dapat memenuhi kebutuhan hidupnya apalagi dengan pemberian uang tip dari pelanggan yang dapat menambah penghasilan.

Makna Ideologi. Jika mengkaji permasalahan alasan Go-Jek menyarankan pelanggan untuk memberikan uang tips melalui Go-Pay adalah karena faktor kemudahan dan kecepatan. Pemberian uang tips dapat dilakukan dengan cepat dan mudah melalui Go-Pay karena dapat dilakukan setelah sampai tujuan yaitu berbarengan ketika pelanggan mengisi rating untuk sang driver. Pelanggan juga tidak perlu lagi mencari uang receh karena pengeluaran melalui Go-Pay akan mengurangi nilai saldo Go-Pay pelanggan tersebut

Makna Denotasi. Makna denotasi pada billboard 2 adalah driver PT. Go-Jek yang merasa senang karena pelanggannya membayar menggunakan Go-Pay. Hal tersebut dikarenakan driver tersebut tidak perlu menyiapkan uang kembalian sehingga lebih efektif dan efisien. Billboard 2 juga menggunakan ukuran yang lumayan besar, background warna terang, cahaya lampu cukup terang dan tidak terlalu ramai dengan berbagai gambar.

Makna Konotasi. Pandangan subyek juga terlihat bahagia yang ditunjukkan pandangan lurus pada handphone dengan senyum mengembang. Demikian juga pelanggan, tersenyum bahagia setelah melihat transaksi Go-Pay berhasil. Tagar lebih baik pakai Go-Pay juga selalu disematkan dalam setiap iklan. Kalimat tersebut merupakan ajakan pihak PT. Go-Jek kepada seluruh pelanggannya agar menggunakan Go-Pay dalam bertransaksi. Kalimat tersebut merupakan ajakan pihak PT. Go-Jek kepada seluruh pelanggannya agar menggunakan Go-Pay dalam bertransaksi.

Makna Ideologi. Pada dasarnya setiap orang menginginkan sesuatu yang mudah dan cepat. Demikian juga pelanggan Go-Jek pastinya membutuhkan pelayanan yang baik, efektif dan efisien. Melalui Go-Pay, PT. GoJek berupaya mengefisienkan waktu si driver dan pelanggan karena dengan e-money Go-Pay pelanggan lebih mudah dalam membayar dan tidak perlu lama menunggu kembalian.

Makna Denotasi. Sekelompok orang yang bahagia karena dapat berbuka puasa bersama. Gambar dibuat ilustrasi namun tetap berkaitan dengan tema iklan. Waktu beriklan adalah bulan Ramadhan sehingga dekorasi yang digunakan juga berbentuk mozaik ramadhan (pojok kanan atas). Hal ini sejalan dengan dua billboard lainnya. Makna denotasi pada billboard 3 adalah kebahagiaan dan hemat jika membayar menggunakan GoPay. Hal tersebut dikarenakan tersedianya diskon pada merchant-merchant tertentu.

Makna Konotasi. Adapun makna konotasi iklan ini adalah bahwa dengan Go-Pay buka puasa menjadi lebih hemat karena Go-Pay menawarkan cashback pada merchant-merchant tertentu. Billboard yang ketiga menggunakan gambar ilustrasi. Kalimat "Silaturahmi Makin Hangat Buka Bareng Makin Hemat" dengan tagar \#nikmati cashback di rekan usaha favoritmu ini secara tidak langsung mengingatkan masyarakat Yogyakarta 
untuk mempererat tali silaturahmi dengan teman, saudara atau rekan bisnis.

Makna Ideologi. Makna ideologi pada billboard 3 adalah pentingnya kedekatan, kemudahan transaksi dan hemat yang dalam hal ini adalah ketika seseorang menggunakan Go-Pay sebagai alat pembayaran. Pembayaran melalui Go-Pay mempermudah dan mempercepat transaksi dan juga hemat. Untuk meningkatkan penggunaan Go-Pay, PT. Go-Jek sering memberikan promo harga yang lebih murah atau diskon tertentu.

\section{KESIMPULAN}

Berdasarkan analisis mengenai Analisis Ikonologi Billboard Go-Pay di Yogyakarta dapat dituliskan secara umum mengenai inti hasil pembahasan bahwa makna ideologi dalam iklan billboard Go-Pay adalah mudah, efisien dan aman. Iklan billboard Go-Pay di Yogyakarta menawarkan hal yang memberikan kemudahan (gampang) untuk dipraktekkan dan mudah untuk melakukan berbagai pembayaran di berbagai merchant GoJek, pembayaran belanja online, pembayaran bensin di SPBU, belanja buku di Gramedia, membayar kopi di Starbucks dan lainnya. Iklan Go-Pay di Yogyakarta juga menawarkan efisiensi pembayaran. Artinya, Go-Pay merupakan alternatif alat pembayaran yang mudah dan cepat sehingga tidak memerlukan waktu yang yang lama ketika pelanggan melakukan transaksi, tidak membingungkan dan tidak merepotkan. Aman artinya bahwa Go-Jek menjamin keamanan bertransaksi melalui Go-Pay sehingga pelanggan tidak perlu ragu jika akan menggunakan Go-Pay. Iklan billboard Go-Pay juga memotivasi pelanggan menggunakan produk/jasa tersebut. Transaksi Go-Pay dikatakan aman karena seluruh transaksi tercatat dalam sistem, recovery transaksi dapat dilihat dan pelanggan tidak perlu membawa uang cash sehingga dapat meminimalisir risiko tindak kriminal.

\section{REFERENSI}

Durianto, S., \& S. (2001). Strategi Menaklukkan Pasar Melalui Riset Ekuitas dan Perilaku Merek. Nasional.

Durianto, S., Widjaja, A. W., \& Supratikno, H. (2003). Inovasi Pasar Dengan Iklan Yang Efektif. Jakarta: Erlangga.

Johar, D. (2015). PENGARUH AIDA (ATTENTION, INTEREST, DESIRE, ACTION) TERHADAP EFEKTIFITAS IKLAN ONLINE (Survei pada Pembeli di Toko Online Adorable Project). Jurnal Administrasi Bisnis S1 Universitas Brawijaya.

Muhammad Rashidi Wahab, M. F. A. (2013). Jurnal Teknologi. Jurnal Teknologi.

Powell, K. (2012). Billboard science. Nature. https://doi.org/10.1038/nj7387-113a

Ratna, N. K. (2001). Teori, Metode, dan Teknik Penelitian Sastra. IJOLTL: Indonesian Journal of Language Teaching and Linguistics. https://doi.org/10.30957/ijoltl.v2i2.281

Sugiyono. (2016). Memahami Penelitian Kualitatif. Bandung: Alfabeta.

Wibowo, I. S. W. (2013). Semiotika komunikasi. ウイルス. 